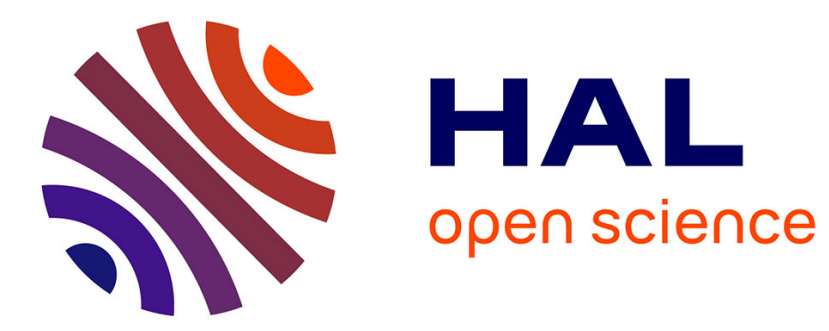

\title{
Dynamic fragmentation of graphite under laser-driven shocks: Identification of four damage regimes
}

Gabriel Seisson, Gabriel Prudhomme, Pierre Antoine Frugier, David Hébert, Emilien Lescoute, Arnaud Sollier, Laurent Videau, Patrick Mercier, Michel Boustié, Laurent Berthe

\section{To cite this version:}

Gabriel Seisson, Gabriel Prudhomme, Pierre Antoine Frugier, David Hébert, Emilien Lescoute, et al.. Dynamic fragmentation of graphite under laser-driven shocks: Identification of four damage regimes. International Journal of Impact Engineering, 2016, 91, pp.68-79. 10.1016/j.ijimpeng.2015.12.012 . hal-02271620

\section{HAL Id: hal-02271620 \\ https://hal.science/hal-02271620}

Submitted on 27 Aug 2019

HAL is a multi-disciplinary open access archive for the deposit and dissemination of scientific research documents, whether they are published or not. The documents may come from teaching and research institutions in France or abroad, or from public or private research centers.
L'archive ouverte pluridisciplinaire HAL, est destinée au dépôt et à la diffusion de documents scientifiques de niveau recherche, publiés ou non, émanant des établissements d'enseignement et de recherche français ou étrangers, des laboratoires publics ou privés. 


\title{
Dynamic fragmentation of graphite under laser-driven shocks: Identification of four damage regimes
}

\author{
G. Seisson a,*, G. Prudhomme a, P.-A. Frugier ${ }^{a}$, D. Hébert ${ }^{\text {b }}$, E. Lescoute ${ }^{a}$, A. Sollier ${ }^{a}$, \\ L. Videau ${ }^{\text {a }}$, P. Mercier ${ }^{\text {a }}$, M. Boustie ${ }^{\text {c }}$, L. Berthe ${ }^{\mathrm{d}}$ \\ a CEA DIF, Bruyères-le-Châtel, 91297 Arpajon Cedex, France \\ b CEA CESTA, 15 avenue des Sablières CS60001, 33116 Le Barp Cedex, France \\ ' Institut P' - UPR3346 CNRS-ENSMA-Université de Poitiers, 1 avenue Clément Ader, 86961 Futuroscope Cedex, France \\ d Laboratoire PIMM - UPR8006 CNRS-Arts et Métiers ParisTech, 151 boulevard de l'Hôpital, 75013 Paris, France
}

Keywords:

Carbon

Damage

PDV

VISAR

Strength

\begin{abstract}
A B S T R A C T
This study presents the results of a large experimental campaign conducted on the Luli2000 laser facility. Thin targets of a commercial grade of porous graphite were submitted to high-power laser-driven shocks leading to their fragmentation. Many diagnostics were used such as high-speed time- and spaceresolved imaging systems (shadowgraphy and photography), laser velocimetry (PDV and VISAR), debris collection and post-mortem X-ray tomography. They provided the loading levels into the targets, the spall strength of the material, the shape and size of debris and the localization of the subsurface cracks. The crossed data reduction of all the records showed their reliability and allowed to get a better insight into the damage phenomena at play in graphite. Thereby, four damage regimes, ranked according to their severity and loading level, were identified. It confirms that laser shocks are very complementary to classical impact tests (plates and spheres) since they ally two-dimensional loadings to the possibility of using both, in-situ and post-mortem diagnostics. Finally, the campaign shall be able to provide large and consistent data to develop and adjust reliable models for shock wave propagation and damage into porous graphite.
\end{abstract}

\section{Introduction}

From the beginning of their development, high-power laser facilities have always been considered as potential calibrated-shock generators [1]. Indeed, the interaction between the laser and the front face of a solid target generates a plasma whose expansion creates a shock wave into the matter that may lead to its failure. Thus, similarities with plate impact experiments [2-5] or hypervelocity impacts $[6,7]$ have been pointed out. Many efforts have been done to understand and predict the mechanical effects of the laser-matter interaction through the development of empirical laws [8-11] and specific hydrocodes [12,13]. As a consequence, high-power lasers are now commonly used in a large scope of shock studies [14-21].

The present authors have recently studied the dynamic behavior of porous graphite under high or hypervelocity impacts of metallic plates and spheres [22-27]. On the one hand, for plate impact experiments, all the phenomena are one-dimensional. Data, exclusively particle velocities (free-surface or interface), are collected during

* Corresponding author. CEA DIF, Bruyères-le-Châtel, 91297 Arpajon Cedex, France. Tel.: +33169264000.

E-mail address: gabriel.seisson@cea.fr (G. Seisson). the experiment and samples cannot be recovered for further postmortem analysis. On the other hand, hypervelocity impacts of spheres generate two-dimensional phenomena and allow sample recovering for fine post-mortem analysis such as micrography and tomography. However, in-situ dynamic observations are less reachable because of time and space uncertainties about the impact.

Hence, the purpose of this paper is to show how a better insight into the two-dimensional damage phenomena of porous graphite can be obtained with well-calibrated and repeatable laser-driven shocks using crossed data reduction from various in-situ and postmortem diagnostics. In Section 2, we present the experimental setup. Then, in Section 3, we discuss the free-surface velocity records in order to estimate the loading levels and the spall strength of our graphite. And finally, in Section 4, we confront, correlate and discuss all the experimental results in order to better understand the damage mechanisms, leading to the identification of four different damage regimes.

\section{Experimental set-up}

Shock experiments have been conducted with a high-power laser facility onto thin graphite targets leading to their fragmentation and/ or perforation. Various diagnostics have been used in order to 
measure the laser spot and pulse, to capture time- and spaceresolved images of the fragmentation and to record the particle velocities. In the same time, reference shots have been done onto well-known materials such as aluminum and tantalum.

\subsection{Facility and diagnostics}

Luli2000 is a high-power laser facility of the Laboratoire pour l'Utilisation des Lasers Intenses (LULI) based at the École Polytechnique (Palaiseau, France) [28]. This laser generates square temporal pulses tunable from 0.5 to $5 \mathrm{~ns}$ and can reach energies up to $1 \mathrm{~kJ}$ at the wavelength of $1064 \mathrm{~ns}$.

Fig. 1 gives a simplified scheme of the experimental set-up. During this campaign, the laser was used at the wavelength of 532 ns with energies between 35 and $700 \mathrm{~J}$, of which about $90 \%$ were delivered in $5 \mathrm{~ns}$ as shown in Fig. 2(a). The targets were placed at the center of the experimental chamber under high-vacuum where two different beams (called SB and NB, i.e. South beam and North beam) were alternatively focused. They formed a negligible angle of 5.5 degrees with the horizontal $x$-axis. They shared the same laser source but had their own amplification chain which allowed larger quantity of shots per day. The focal spot of each beam was spatially shaped just before the experiment chamber by means of phase plates that made the beams axisymmetrical and pseudo-Gaussian (see Fig. 2(b) and $2(\mathrm{c})$ ).
The particle velocities of the rear face of the targets were measured by VISAR [29] which has a good temporal resolution. However, its need of a strong return signal can be an issue when the measured surface gets highly deformed and loses its reflectivity. Hence, we also used photonic Doppler velocimetry (PDV) [30-32] that has a lower temporal resolution but is capable to record multiple velocities despite weak return signals (around a few percents of the original one). Two PDV probes with 1-mm-diameter beams were placed in the $x-y$ plan, each forming an angle with the $x$-axis $\left(\alpha_{1}\right.$ and $\alpha_{2}$ respectively). They were pointed to the back face of the targets measuring its velocity and then the velocity of the ejected fragments.

For some shots, VISAR was replaced by an open cube filled with varagel, a gel derivated from paraffin with a density close to the water one. Placed at a few centimeters from the back face, this collector captured debris without damaging them in order to measure and analyze them by means of tomography [33].

The time- and space-resolved laser shadowgraphy recorded fragments ejected from the targets back face [34]. A 527-nm continuous laser enlightened two amplified cameras that took pictures of the shadow of the ejecta according to the $x-z$ plan. Each camera made two images at different times with an exposure time of $5 \mathrm{~ns}$. The exact instant of the capture was known thanks to a synchronization system between the laser facility and all the diagnostics.

High-speed photography was obtained by pulsed-laser illumination [35]: two 10-ns pulses of second harmonic YAG laser

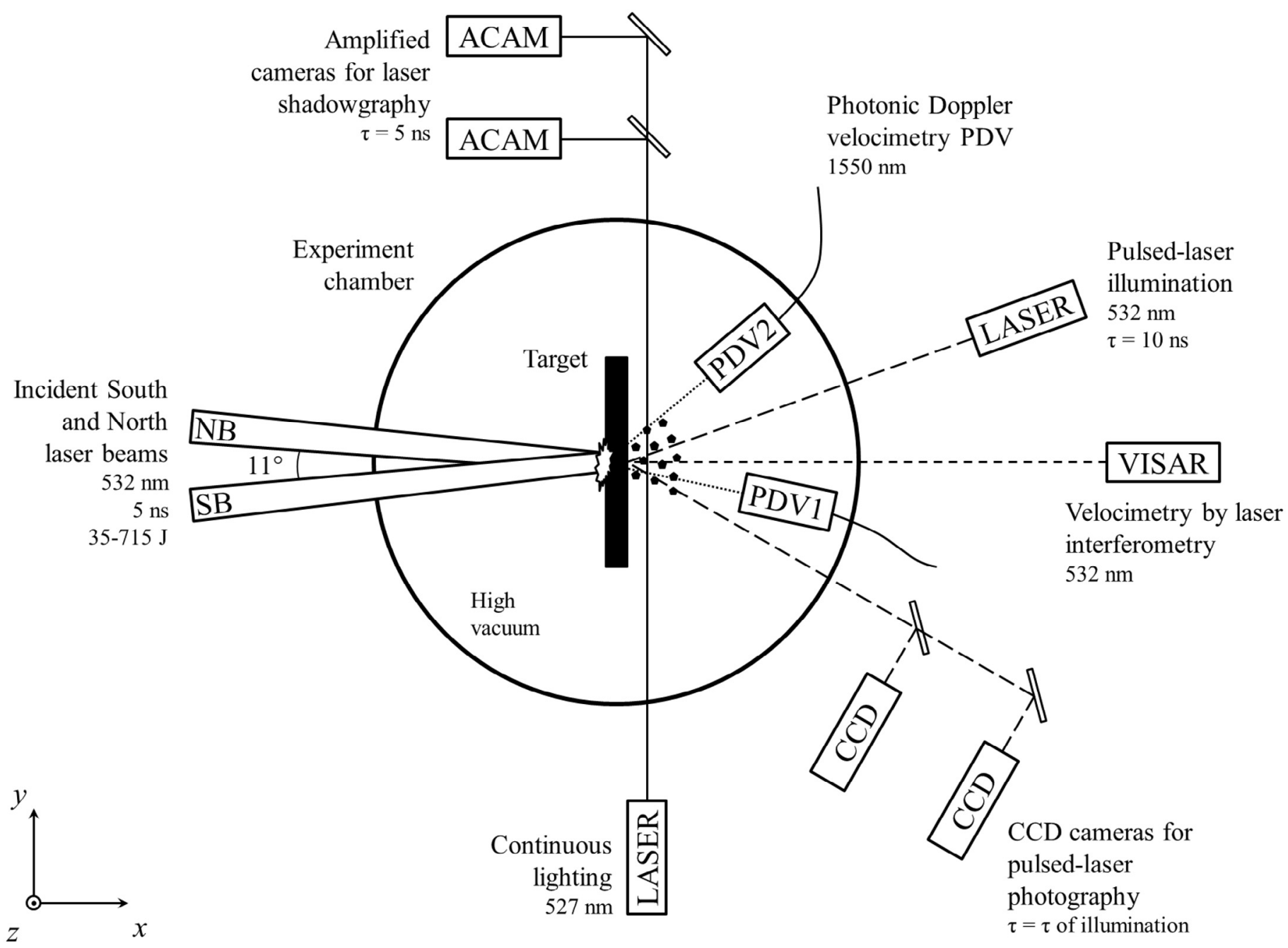

Fig. 1. Simplified scheme of the experimental set-up. Two different types of diagnostic have been used: laser velocimetry, and time-resolved laser imaging. 


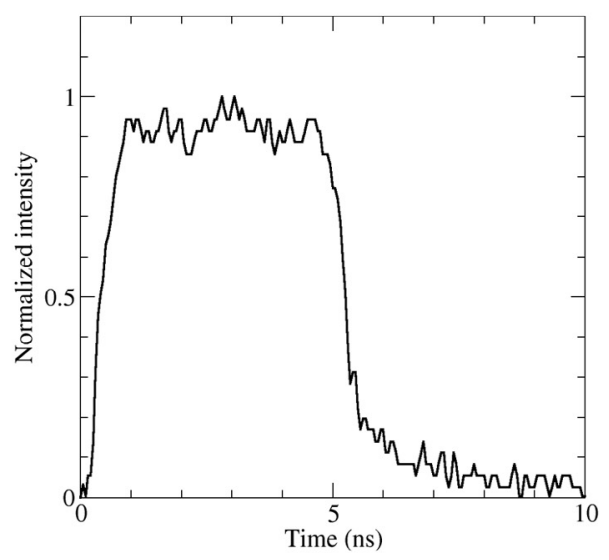

(a) Example of temporal pulse.

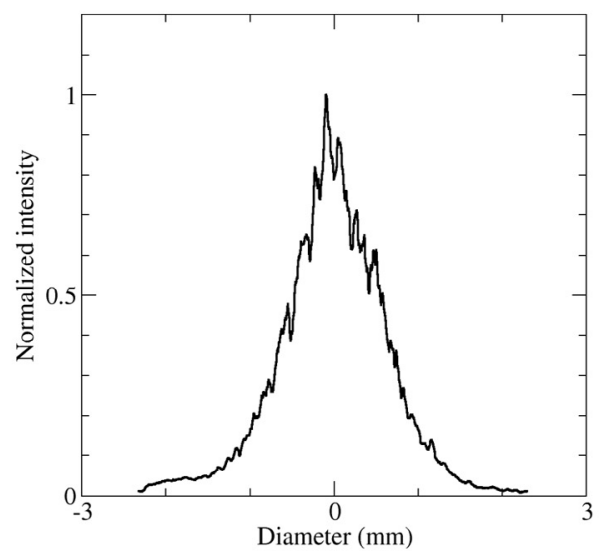

(b) Spatial profile of the NB.

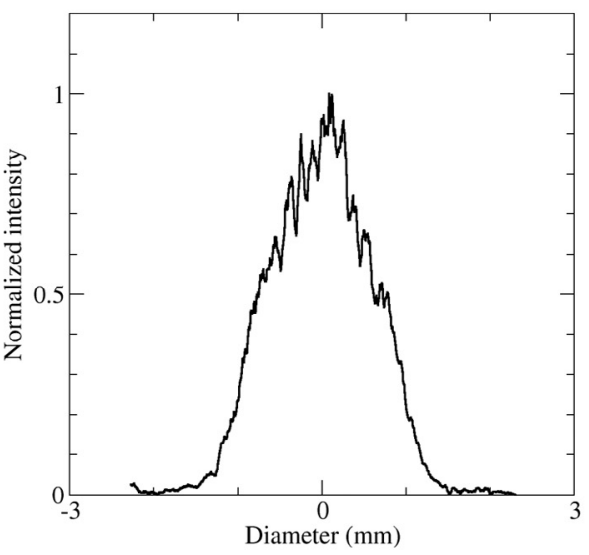

(c) Spatial profile of the SB.

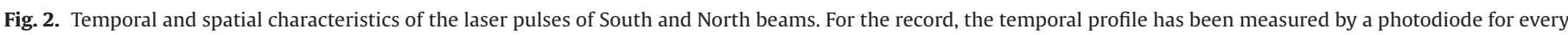
shot. Very stable, the spatial profiles have been gauged at regular intervals with a CCD camera.

lightened the scene, hence freezing the movement of the rear surface. The apparatus delivered two high-resolution frames, even when fragment velocities exceeded several hundreds of meters per second. Light was fed through bundles of multimode optical fibers providing flexibility in its positioning and, as a side effect, operating a significant smoothing of both objective and subjective speckles. Its residual contrast was estimated at only $14 \%$. Each frame was captured by a CCD camera with sampling $2048 \times 2048$ pixels and 500 ns framing for spurious light rejection; an interferometric filter could also be implemented to further reject unwanted light signals (plasma, PDV probes, etc.).

\subsection{Targets and shot configurations}

The shots of the campaign are summarized in Table 1 giving the characteristics of the targets as well as the laser and diagnostic parameters. As mentioned above, reference shots were performed onto 6061-T6 aluminum and tantalum targets whose respective thicknesses were 250 and $125 \mu \mathrm{m}$. But most of the shots were done onto 18 -mm square plates of EDM3 graphite whose thickness varied from 0.75 to $2.5 \mathrm{~mm}$.
EDM3 is a macroscopically isotropic commercial grade of graphite made by POCO $[36,37]$ and has been extensively investigated by the present authors $[22,38]$ in the context of understanding the dynamic behavior of matrices from carbon-carbon composites. It is about $22 \%$ porous with a density of $1.754 \mathrm{~g} / \mathrm{cm}^{3}$. A binarised optical micrography of a healthy sample of EDM3 (after cutting and polishing) is displayed in Fig. 3. It shows that the side of the cubic Representative Volume Element (RVE) is of the order of $50 \mu \mathrm{m}$, i.e. from 15 to 50 times less than the target thickness and around 40 times less than the laser spot diameter. The main features of EDM3 that may be useful to the reader and to the discussions are recalled in Table 2.

Finally, the back face of the targets were covered of a 1- $\mu \mathrm{m}$ aluminum layer in order to better reflect laser diagnostics.

\section{Velocimetry analysis}

In this section, we present and analyze the VISAR and the PDV records in order to evaluate the difference between South and North beams, the spall strength of EDM3 and the mechanical loading endured by the targets.

Table 1

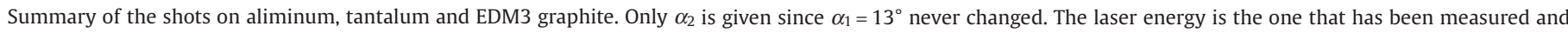

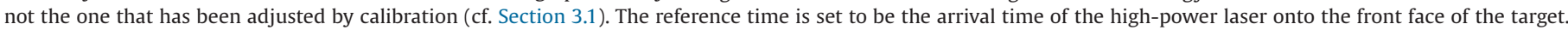

\begin{tabular}{|c|c|c|c|c|c|c|c|c|c|c|c|c|c|}
\hline \multirow[t]{2}{*}{ Shot number } & \multicolumn{2}{|l|}{ Target } & \multicolumn{2}{|l|}{ Laser } & \multicolumn{2}{|c|}{ Velocimetry } & \multicolumn{4}{|c|}{ Shadowgraphy ( $\mu$ s) } & \multicolumn{2}{|c|}{ Photography ( $\mu \mathrm{s})$} & \multirow{2}{*}{$\begin{array}{l}\text { Debris } \\
\text { collector }\end{array}$} \\
\hline & Material & Thick $(\mu \mathrm{m})$ & Beam & Energy $(\mathrm{J})$ & VISAR & $\alpha_{2}$ & IMG1 & IMG2 & IMG3 & IMG4 & IMG1 & IMG2 & \\
\hline 3 & $\mathrm{Al}$ & 250 & $S$ & 116 & $x$ & $15^{\circ}$ & 1.5 & 2 & 3 & 4 & 0.46 & 0.54 & - \\
\hline 4 & $\mathrm{Al}$ & 250 & $\mathrm{~N}$ & 572 & - & $15^{\circ}$ & 0.6 & 1 & 1.4 & 1.8 & - & 0.48 & - \\
\hline 5 & EDM3 & 2500 & $\mathrm{~S}$ & 215 & $\times$ & $15^{\circ}$ & 5 & 16 & 30 & 50 & 10.44 & 16.44 & - \\
\hline 6 & EDM3 & 2500 & $\mathrm{~N}$ & 715 & $\times$ & $15^{\circ}$ & 5 & 16 & 30 & 50 & 10.44 & 16.44 & - \\
\hline 7 & EDM3 & 750 & $\mathrm{~S}$ & 121 & $\times$ & $15^{\circ}$ & 5 & 16 & 30 & 50 & 10.44 & - & - \\
\hline 8 & EDM3 & 750 & $\mathrm{~N}$ & 652 & $x$ & $15^{\circ}$ & 4 & 7 & 10 & 13 & 3.36 & 9.36 & - \\
\hline 9 & EDM3 & 1000 & $\mathrm{~N}$ & 636 & $\times$ & $42^{\circ}$ & 3 & 5 & 8 & 10 & 2.36 & 8.36 & - \\
\hline 10 & EDM3 & 1000 & $\mathrm{~S}$ & 235 & $\times$ & $42^{\circ}$ & 3 & 8 & 15 & 20 & 4.36 & 10.34 & - \\
\hline 11 & EDM3 & 1500 & $\mathrm{~N}$ & 608 & $\times$ & $42^{\circ}$ & 4 & 10 & 15 & 20 & 4.36 & 10.34 & - \\
\hline 12 & EDM3 & 1500 & $S$ & 189 & $\times$ & $42^{\circ}$ & 10 & 20 & 30 & 50 & - & - & - \\
\hline 13 & EDM3 & 2000 & $\mathrm{~N}$ & 564 & $\times$ & $42^{\circ}$ & 10 & 30 & 50 & 100 & 10.34 & 30.34 & - \\
\hline 14 & EDM3 & 750 & $\mathrm{~S}$ & 35 & $x$ & $42^{\circ}$ & 5 & 10 & 30 & 50 & 10.34 & 30.34 & - \\
\hline 15 & EDM3 & 750 & S & 259 & - & $42^{\circ}$ & 5 & 16 & 30 & 50 & 10.34 & 30.44 & $\times$ \\
\hline 16 & EDM3 & 750 & $\mathrm{~N}$ & 167 & $\times$ & $42^{\circ}$ & 5 & 10 & 20 & 30 & 10.34 & 30.34 & - \\
\hline 17 & EDM3 & 750 & $S$ & 547 & $\times$ & $42^{\circ}$ & 2 & 4 & 8 & 10 & 2.4 & 8.4 & - \\
\hline 18 & EDM3 & 1000 & $\mathrm{~N}$ & 342 & $x$ & $42^{\circ}$ & 3 & 9 & 15 & 20 & 3.4 & 9.4 & - \\
\hline 20 & $\mathrm{Ta}$ & 125 & $\mathrm{~N}$ & 644 & $\times$ & $42^{\circ}$ & 1 & 2 & 4 & 7 & 1.44 & 7.36 & - \\
\hline 26 & EDM3 & 1000 & $\mathrm{~N}$ & 415 & - & $42^{\circ}$ & - & - & - & - & - & 9.4 & $\times$ \\
\hline 27 & EDM3 & 1000 & $S$ & 467 & - & $42^{\circ}$ & - & - & - & - & 3.4 & 9.4 & $\times$ \\
\hline
\end{tabular}




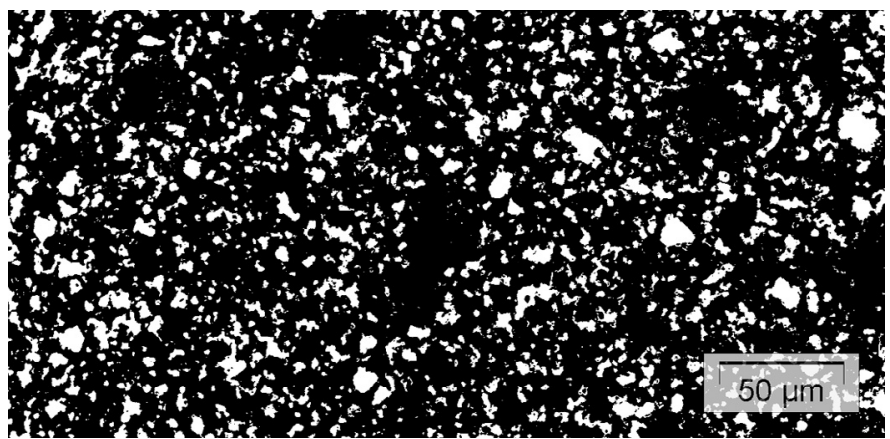

Fig. 3. Binarized optical micrography of a healthy sample of EDM 3 after cutting and polishing. Material matrix appears in black whereas voids are in white. The Representative Volume Element (RVE) is about $50 \times 50 \times 50 \mu \mathrm{m}$.

Table 2

Main characteristics of the EDM3 graphite according to references 22 and 38. The Young modulus was exctracted from tensile and compression tests and confirmed by ultrasonic analysis that also gave the sound velocities.

\begin{tabular}{llr}
\hline Density $\rho_{0}\left(\mathrm{~kg} / \mathrm{m}^{3}\right)$ & Porous & 1754 \\
& Compact & 2265 \\
Failure stress $\sigma_{r}(\mathrm{MPa})$ & Tension & 70 \\
& Compression & 140 \\
Failure strain $\varepsilon_{r}(\%)$ & Tension & 1 \\
& Compression & 8 \\
Young modulus $E(\mathrm{GPa})$ & & $11-12$ \\
Bulk sound velocity $C_{0}(\mathrm{~m} / \mathrm{s})$ & 2212 \\
Fracture toughness $K_{I c}(\mathrm{MPa} \cdot \sqrt{m})$ & & $0.8-1.2$ \\
Porosity $\gamma_{0}(\%)$ & 22 \\
\hline
\end{tabular}

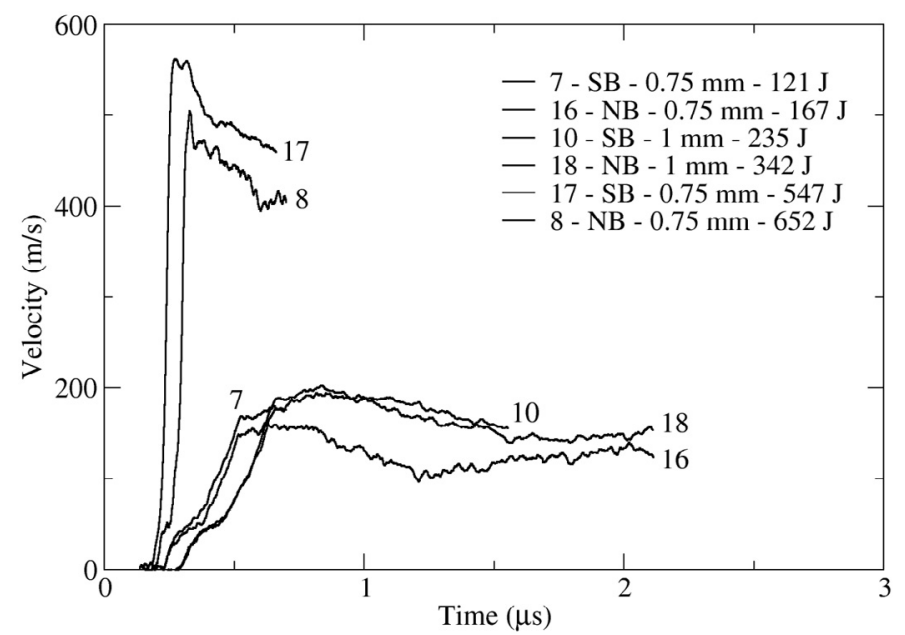

Fig. 4. Free surface velocities for three couples of similar shots performed with different beams. It clearly points out the difference between NB and SB. For clarity, noise has been reduced.

\subsection{North beam vs. South beam}

Before presenting all the VISAR records, the difference between NB and SB has to be pointed out. The shots conducted on both beams must be considered as two distinct series. This is demonstated by Fig. 4 that presents VISAR signals for three couples of shots with identical thicknesses. For each couple, the energy of NB is slightly higher than the one of the SB but this is not the case of the free surface velocity. For example, the energy of shot \#8 is $20 \%$ higher than shot \#17 but its velocity is $15 \%$ lower. For clarity and consistency we specify in the following the laser beam used for each shot adding the letter $\mathrm{S}$ or $\mathrm{N}$ before the shot number, e.g. S17 and N8.

The most obvious reason of such a discrepancy between NB and SB in spite of similar energies is the shape of their respective focal spots that are rather different. A significant part of the announced energy can be spent in the wings of the Gaussian spot at very low intensities but over a large area. Thus, it is necessary to know the exact amount of energy contained in the useful part of the spot, i.e. the central part where the intensity is high enough to generate a shock wave into the target. Therefore, reference shots onto wellknown materials that are aluminum and tantalum have been performed. A calibration process consisting in computations of lasermatter interaction and shock wave propagation (not presented here) revealed that the useful part of the focal spot contains $45 \%$ of the measured energy for NB and $80 \%$ for SB which is consistent with the VISAR records plotted in Fig. 4.

\subsection{Loading levels}

Fig. 5 gathers the VISAR records obtained for the shots onto EDM3. Note that the time uncertainty is of $\pm 2 \mathrm{~ns}$. The set of shots covered a large field of loading since the free surface velocities range from 50 to $560 \mathrm{~m} / \mathrm{s}$.

Using the acoustic approximation, one can roughly evaluate the maximum pressure $P_{m}$ of the shock wave breaking out of the target back face by means of the following expression:

$P_{m}=\frac{1}{2} \rho_{0} C_{0} U_{m}$

where $\rho_{0}$ and $C_{0}$ are the initial density and the bulk sound velocity of the target material and $U_{m}$ is the maximum free surface velocity. The pressure $P_{m}$ of each shot on graphite is given in Table 3 , ranging from 0.1 to $1.1 \mathrm{GPa}$. But this must be considered with caution, because if the acoustic approximation is quite well adapted to dense materials where the sound velocity does not vary so much with the pressure, this is not the case for porous materials such as EDM3 where the sound velocity decreases first and then increases because of the compaction phenomenon. However, it gives good orders of magnitude.

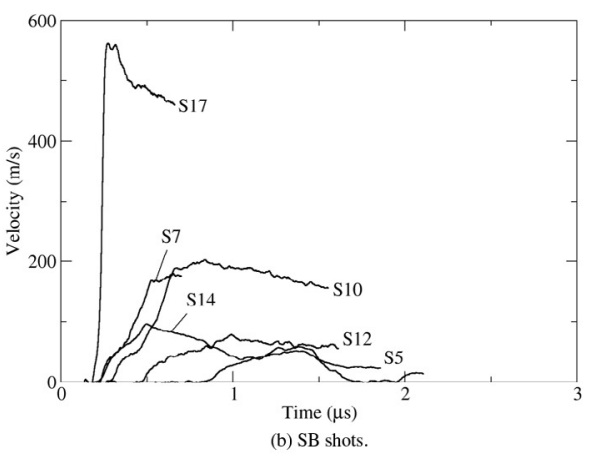

Fig. 5. VISAR records of shots onto EDM3 graphite. Noise has been reduced. 
Table 3

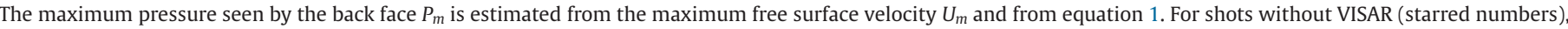
$U_{m}$ is exctracted from PDV signals. The ablation pressure $P_{a b}$ is calculated thanks to the maximum calibrated laser intensity $I_{m}$ and to equation 2 .

\begin{tabular}{|c|c|c|c|c|c|c|c|c|c|c|c|c|c|c|c|c|}
\hline Shot number & 05 & 06 & 07 & 08 & 09 & 10 & 11 & 12 & 13 & 14 & $15^{*}$ & 16 & 17 & 18 & $26^{*}$ & $27^{*}$ \\
\hline Laser beam & $S$ & $\mathrm{~N}$ & S & $\mathrm{N}$ & $\mathrm{N}$ & $S$ & $\mathrm{~N}$ & $\mathrm{~S}$ & $\mathrm{~N}$ & $S$ & S & $\mathrm{N}$ & $\mathrm{S}$ & $\mathrm{N}$ & $\mathrm{N}$ & $\mathrm{s}$ \\
\hline Thickness (mm) & 2.5 & 2.5 & 0.75 & 0.75 & 1 & 1 & 1.5 & 1.5 & 2 & 0.75 & 0.75 & 0.75 & 0.75 & 1 & 1 & 1 \\
\hline$U_{m}(\mathrm{~m} / \mathrm{s})$ & 51 & 77 & 169 & 511 & 332 & 201 & 163 & 78 & 99 & 97 & 272 & 162 & 564 & 194 & 190 & 320 \\
\hline$P_{m}(\mathrm{MPa})$ & 99 & 149 & 327 & 991 & 644 & 390 & 316 & 151 & 192 & 188 & 528 & 314 & 1094 & 376 & 369 & 621 \\
\hline$I_{m}\left(\mathrm{TW} / \mathrm{cm}^{2}\right)$ & 1.57 & 3.94 & 0.89 & 3.59 & 3.50 & 1.72 & 3.35 & 1.38 & 3.11 & 0.26 & 1.89 & 0.92 & 4.00 & 1.88 & 2.29 & 3.42 \\
\hline$P_{a b}(\mathrm{GPa})$ & 43.5 & 90.6 & 27.4 & 84.2 & 82.5 & 46.7 & 79.6 & 39.2 & 74.9 & 10.2 & 50.4 & 28.3 & 91.7 & 50.2 & 58.6 & 80.8 \\
\hline
\end{tabular}

It is interesting to compare $P_{m}$ to the ablation pressure generated on the front face by the plasma expansion. In the case of aluminum, the Grün formula [9] gives good results:

$P_{a b}=1440\left(0.8 \frac{I_{m}}{10^{5}}\right)^{0.8}$

with $P_{a b}$ the ablation pressure in GPa and $I_{m}$ the maximum laser intensity expressed in $\mathrm{GW} / \mathrm{cm}^{2}$. There is no such empirical law for graphite but we have shown that the Grün formula gives good order of magnitude for graphite at intensities around $1 \mathrm{TW} / \mathrm{cm}^{2}$ [25]. The intensity used here is an equivalent one calculated after the calibration process in the case of a homogeneous top-hat spot whose diameter has been ajusted to conserve the power. Table 3 gives the ablation pressure of each shot deduced from equation 2 .

The immense difference (two orders of magnitude) between $P_{a b}$ and $P_{m}$ must be noticed. It shows a strong attenuation of the shock wave during its propagation through the graphite target. This phenomenon is linked to the target thickness, to the very short laser pulse and to the fact that the velocities of the release waves in porous materials are much higher than the shock wave one.

\subsection{Spall strength}

Fig. 6 shows the back face of shot S27 captured by the laser imaging at $3.4 \mu \mathrm{s}$ after the laser pulse begining. The Gaussian shape of the beam leads to a strong bulge of the surface degrading its reflectivity. It certainly happened right after the shock break-out instant that can explain the fact that VISAR signal is lost before any pull-back. Thus, VISAR is very useful for recording the shock front but for spall phenomenon, PDV must take over.

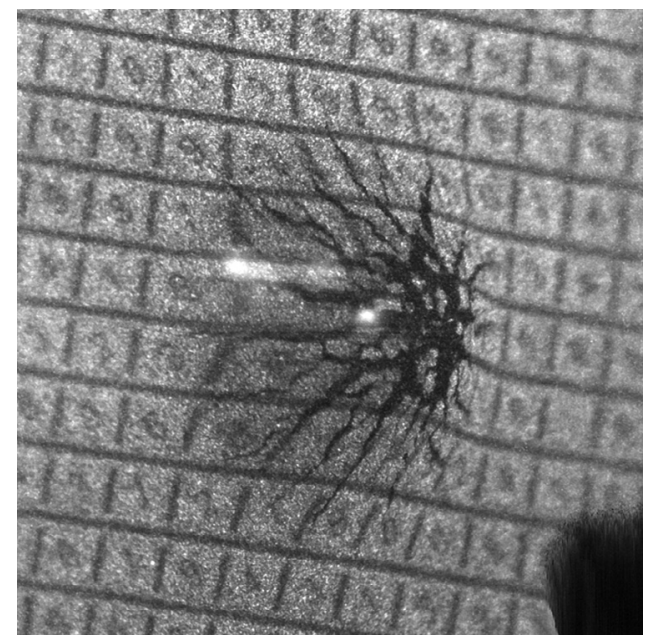

Fig. 6. Tilted view of the back face of shot $S 27,3.4 \mu$ s after the laser pulse. The surface is strongly deformed under the effect of the shock. The black area in the right-handside bottom corner is due to the sensor damage. White trails are a residue of the PDV pumping laser.

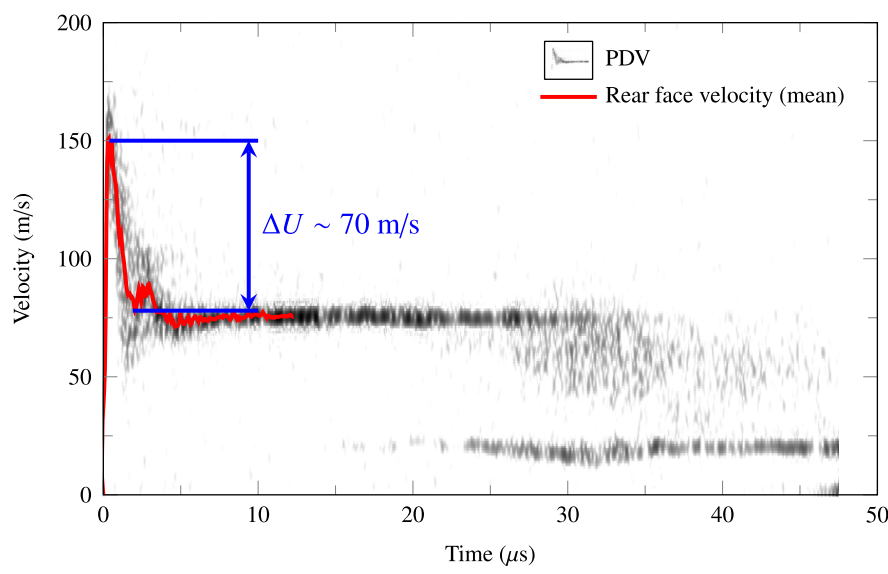

Fig. 7. Spectrogram S7-PDV1. The second constant velocity signal around $20 \mathrm{~m} / \mathrm{s}$ after $20 \mu \mathrm{s}$ is hardly understandable without the help of the imaging systems. Velocities are corrected by the cosine of $\alpha_{1}$.

Remind that the PDV probes use a collimated beam whose diameter is above $1 \mathrm{~mm}$. It means they record all the velocities over a surface equal to the beam area. As a result, we get a spectrum of velocities whose maximum values are theoritically related to the center of the stressed area. Nevertheless, a correction is needed in order to take into account the angles $\alpha_{i}$ dividing the velocities by the their respective cosine (in the hypothesis of colinearity between the $x$-axis and the surface and/or debris motion).

The spectrogram of S7-PDV1 plotted in Fig. 7 confirms the maximum free surface velocity of $170 \mathrm{~m} / \mathrm{s}$ recorded by VISAR, which is the case $( \pm 10 \%)$ for every shots with both PDV and VISAR. Then, after $4 \mu \mathrm{s}$, it clearly shows a spall flight with a constant velocity signal around $75-80 \mathrm{~m} / \mathrm{s}$.

Averaging the velocities before $10 \mu$ s gives a unique velocity signal where a pull-back is clearly visible with a $\Delta U \sim 70 \mathrm{~m} / \mathrm{s}$. One can estimate the spall strength by:

$\sigma_{s p}=-\frac{1}{2} \rho_{0} C_{0} \Delta U$

It gives $\sigma_{s p}=-135 \mathrm{MPa}$ a value sensibly higher than the static tensile strength of -70 MPa given in Table 2. However, given the porosity of EDM3, the acoustic approximation must be considered with caution. Anyway, the existence of a planar spall is uncertain because of the Gaussian shape of the focal spot that complexifies the phenomenon. In fact, after $20 \mu$ s, the signal lose its intensity and a new trail progressively begins around $20-25 \mathrm{~m} / \mathrm{s}$. The joint use of PDV and imaging systems will help to understand this phenomenon.

\section{Correlation of the experimental results}

Many in-situ diagnostics have been simultaneously used during the campaign. Each of them gives partial information about the shock propagation into the target or about its fragmentation. They were 
completed by post-mortem tomographies of the recovered targets and debris, informing about damage. The purpose of the following is to correlate all these results in order to better understand the damage phenomenology of graphite under laser-induced shock.

\subsection{Representative shots}

A first data reduction allowed us to visually identify four different damage regimes to which almost all the shots can be linked to. Each of the four shots discussed in this section is representative of a particular damage regime.

\subsubsection{Shot $\mathrm{S} 7-0.75 \mathrm{~mm}-0.89 \mathrm{TW} / \mathrm{cm}^{2}$}

Fig. 8 gives the results of the two time-resolved imaging systems used during shot S7. Surprisingly, they evidence two spall levels: the one that is ejected first looks like an Asian conical hat and is constituted of multiple debris; it is followed by a unique spall shaped like a cymbal or a saucer recessed of the first stage of debris. The distance between those two stages is increasing with time which indicates the first one is moving faster.

We drew the position and the size of the PDV1 beam onto the shadowgraphy images. In reality, probes were placed in the $x-y$ plan instead of the $x-z$ plan as suggested here but this is not much inaccurate because of the axisymmetry of the experiment. In this manner, one sees that the Asian hat goes first through the PDV beam. Then, between 16 and $50 \mu \mathrm{s}$, the cymbal progressively intercepts the beam. Thus, the velocity signal around $75-80 \mathrm{~m} / \mathrm{s}$ seen on Fig. 9 should correspond to the first spall level whereas the one around $20-25 \mathrm{~m} / \mathrm{s}$ should belong to the second stage. It is easily verifiable thanks to the time- and space-resolved shadowgraphy which enables to know the average speed of an object $V_{a v}$ between two images, using the simple formula:

$V_{a v}=\frac{x_{2}-x_{1}}{\Delta t}$

According to Fig. 8(a), it leads to $88 \mathrm{~m} / \mathrm{s}$ for the first level and $28 \mathrm{~m} / \mathrm{s}$ for the second one. The order of magnitude is rather good even if a slight discrepancy exists. It probably comes from the fact that the two methods do not consider the velocity of the same points, those possibly varying despite the almost axisymmetry of the experiment.

\subsubsection{Shot $\mathrm{S} 15-0.75 \mathrm{~mm}-1.89 \mathrm{TW} / \mathrm{cm}^{2}$}

The same analysis is feasible for totally different shots shuch as shot S15, conducted at higher energy and whose results are given in Fig. 9. With shadowgraphy, one identifies three successive debris levels whose velocities are around $250 \mathrm{~m} / \mathrm{s}$ for the first one (L1), $140 \mathrm{~m} / \mathrm{s}$ (L2) and $85 \mathrm{~m} / \mathrm{s}$ (L3). They are represented on the spectrogram of PDV1 by means of three horizontal lines. The identification of the slower level is the easiest because it is the one that stays the longest in the PDV beam (from $10 \mu \mathrm{s}$ ).

\subsubsection{Shot $\mathrm{S} 17-0.75 \mathrm{~mm}-4 \mathrm{TW} / \mathrm{cm}^{2}$}

Until now, we followed the assumption that the motion of the ejecta was exclusively along the $x$-axis and thus, the velocity measured by PDV1 could simply be corrected by the cosine of $\alpha_{1}$. It was rather accurate for shots S7 and S15. but it is less obvious in the case of shot S17 conducted at even higher energy whose results are outlined in Fig. 10.

Beyond the first instants, one cannot know the exact velocity along the $x$-axis because the debris cloud takes the shape of an expending sphere, also moving along this axis. Hence, the record is only a projection of the particle velocity along the probe axis. This is an incomplete measure whose bias depends not only on the time but also on the observed particle. When the PDV beam skims over the sphere periphery, it records in the same time particle velocities with strongly different directions. That is why no angle correction has been done on the PDV spectrogram of Fig. 10(a). Nonetheless, at late instants one observes a constant velocity signal around $100 \mathrm{~m} / \mathrm{s}$ that according to shadowgraphy seems to be the one of the cone following the sphere.

\subsubsection{Shot $\mathrm{N} 13-2 \mathrm{~mm}-3.11 \mathrm{TW} / \mathrm{cm}^{2}$}

The reading of shot N13 is much more simple as shown in Fig. 11. Except small central debris due to overintensities of the focal spot observable in Fig. 2(b), imaging systems evidence the creation and the flight of a single spall at very low velocity in the order of $15 \mathrm{~m} / \mathrm{s}$. This fact is confirmed by the sole constant velocity signal appeared on PDV1. Moreover, one notes that the pull-back observed on the spectrogram $(\Delta U \sim 70 \mathrm{~m} / \mathrm{s})$ corroborates the one recorded for shot S7 (see Section 3.3).

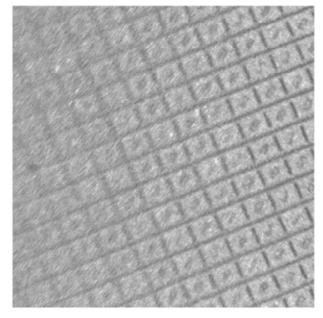

(a) Laser imaging at $\mathrm{t}=0$.

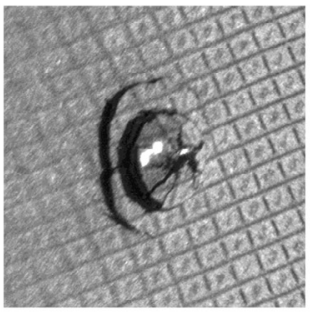

(b) $\mathrm{t}=10.44 \mu \mathrm{s}$.

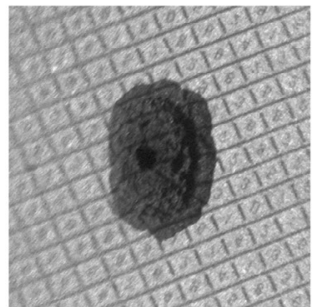

(c) Post-mortem.

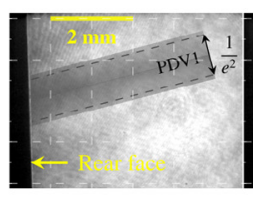

$0 \mu \mathrm{s}$

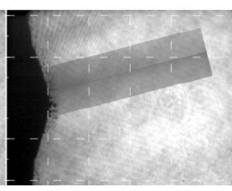

$5 \mu \mathrm{s}$

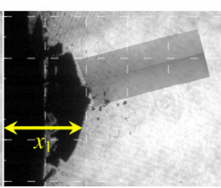

$16 \mu \mathrm{s}$

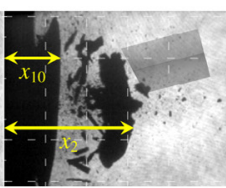

$30 \mu \mathrm{s}$

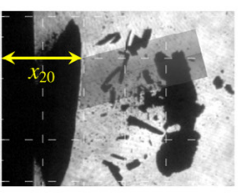

$50 \mu \mathrm{s}$

(d) Laser shadowgraphy at different instants. The PDV1 beam is symbolized in gray along with its $1 / e^{2}$ diameter,

i.e. $1 \mathrm{~mm}$. This diameter is equal to the distance between the two points on the power distribution that are equal to $1 / e^{2}(0.135)$ times the maximum value. High-power laser came from left.

Fig. 8. Shot $\mathrm{S} 7-0.75 \mathrm{~mm}-0.89 \mathrm{TW} / \mathrm{cm}^{2}$. Results of the laser imaging systems at different instants after the high-power laser pulse. 


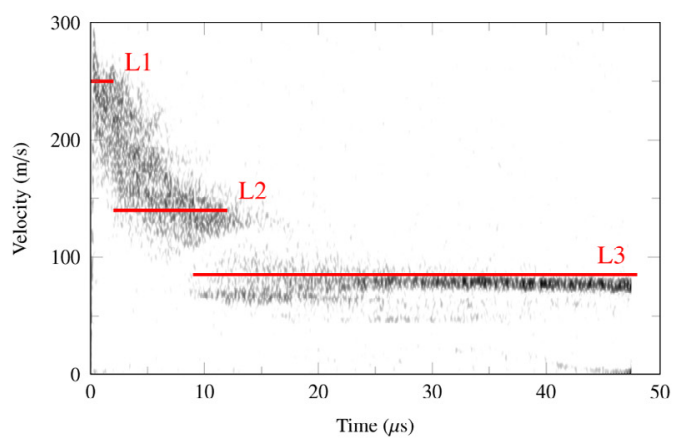

(a) Spectrogram of PDV1.

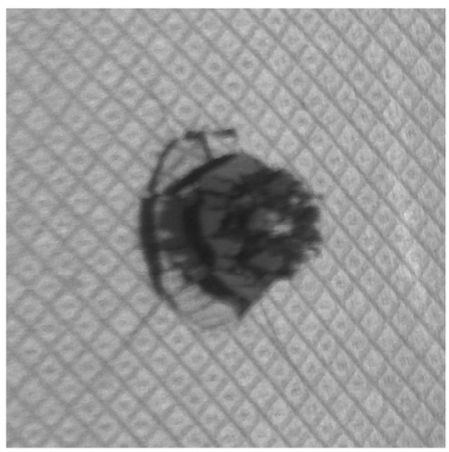

(b) Laser imaging at $\mathrm{t}=10.44 \mu \mathrm{s}$.

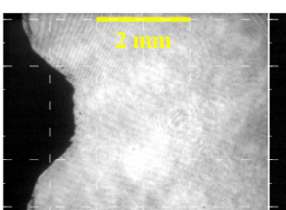

$5 \mu \mathrm{s}$

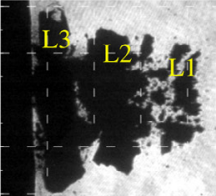

$16 \mu \mathrm{s}$

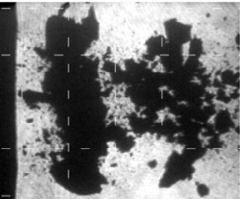

$30 \mu \mathrm{s}$

(c) Laser shadowgraphy at different instants.

Fig. 9. Shot S15 $-0.75 \mathrm{~mm}-1.89 \mathrm{TW} / \mathrm{cm}^{2}$. Laser imaging and shadowgraphy at different instants and debris velocity recorded by PDV.

\subsection{Damage regimes}

As said previously, shots N13, S7, S15 and S17 were not randomly selected. They are representative of four different damage regimes identified, proceeding from the data reduction of the campaign. Name them D1 to D4 according to their physical aspect and severity:

Regime D1: formation of a single conical spall;

Regime D2: apparition of a double spall with a multi-fragmented first stage and a one-piece second one;
Regime D3: multiple fragmentation of the target into few debris levels;

Regime D4: explosion of the target with a sphere-shaped cloud constitued of numerous debris of small size.

\subsubsection{Identification and origins}

The data reduction of the other shots allows to identify those linked to one or the other regime based on the damage aspect as ranked in Table 4. Because damage necessarily depends on loading

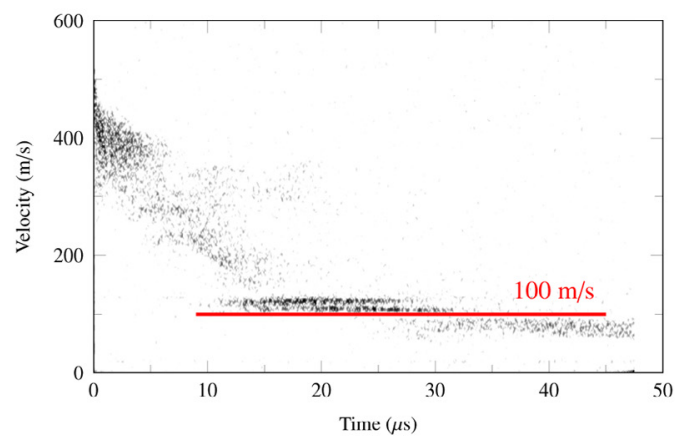

(a) Spectrogram of PDV1.

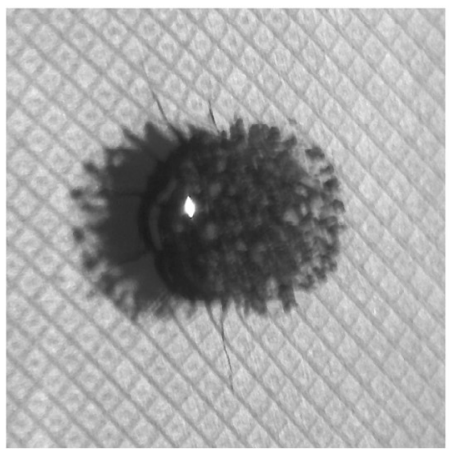

(b) Laser imaging at $\mathrm{t}=8.4 \mu \mathrm{s}$.

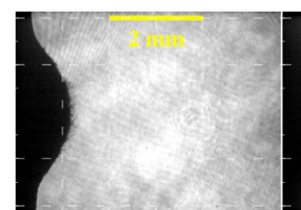

$2 \mu \mathrm{s}$

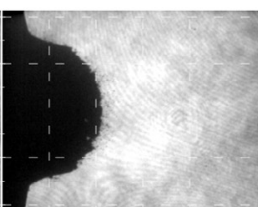

$4 \mu \mathrm{s}$

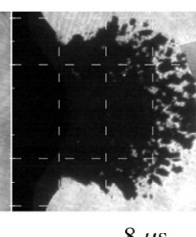

$8 \mu \mathrm{s}$

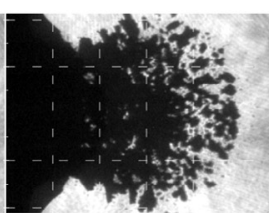

$10 \mu \mathrm{s}$

(c) Laser shadowgraphy at different instants. The beam of PDV1 is drawn in gray.

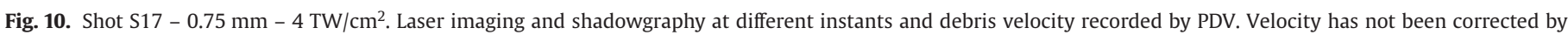
the cosine of $\alpha_{1}$. 


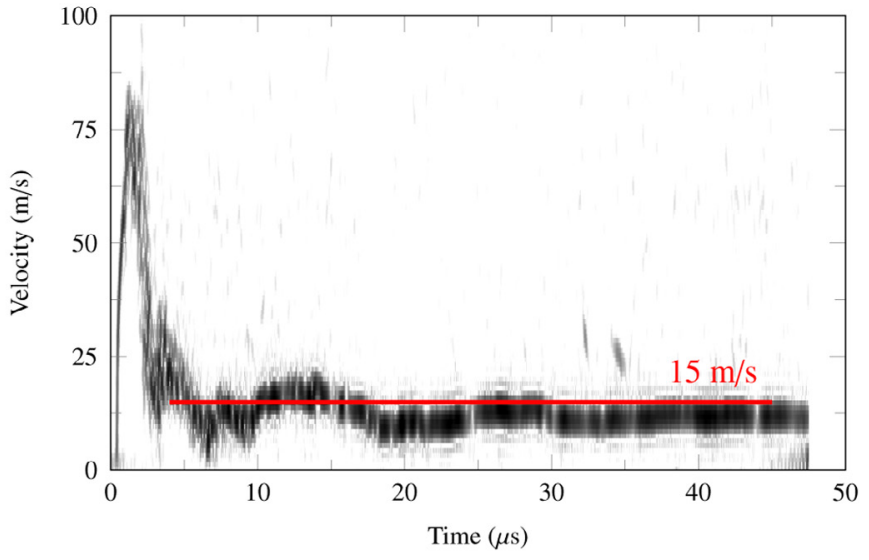

(a) Spectrogram of PDV1.

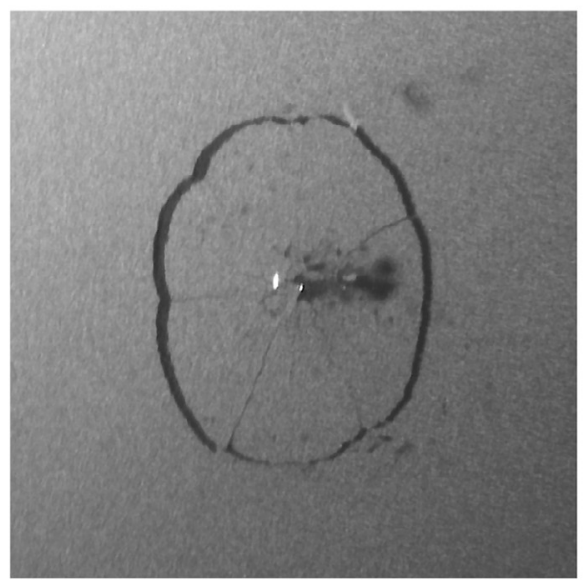

(b) Laser imaging at $\mathrm{t}=30.34 \mu \mathrm{s}$.

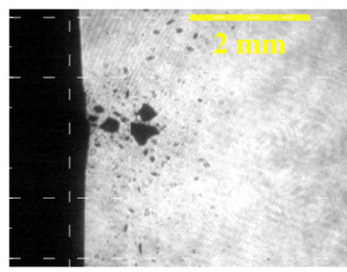

$30 \mu \mathrm{s}$

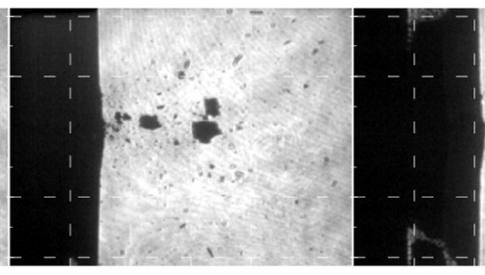

$50 \mu \mathrm{s}$

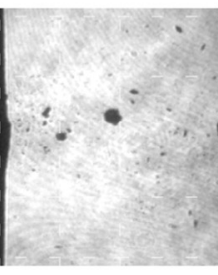

$100 \mu \mathrm{s}$

(c) Laser shadowgraphy at different instants.

Fig. 11. Shot $\mathrm{N} 13-2 \mathrm{~mm}-3.11 \mathrm{TW} / \mathrm{cm}^{2}$. Laser imaging and shadowgraphy at different instants and debris velocity recorded by PDV.

conditions, the maximum intensity, the maximum pressure seen by the back face and the maximum free surface velocity are recalled.

Shots S5, N6, S10, S12, S14 and N16 are not ranked, either because there is no apparent damage or because the latter does not look like the one of any other shot. It clearly appears that the belonging of a shot to a regime is not directly related to the laser intensity, i.e. to the ablation pressure. For example, in D2 the laser intensities are varying from simple to double; and the unique intensity of D1 $\left(\mathrm{N} 13-3.11 \mathrm{TW} / \mathrm{cm}^{2}\right)$ is higher than the lowest one of D3 $\left(\mathrm{S} 15-1.89 \mathrm{TW} / \mathrm{cm}^{2}\right)$. Nevertheless, the back face velocities are very close to each other for shots from a same regime. This phenomenon is illustrated by Fig. 12 that gives an overview of the four regimes for each beam. In the case of NB, the ablation pressure is constant and the target thickness is varying whereas it is the opposite for $\mathrm{SB}$. The only common point between the shots of one regime is the free surface velocity, hence the loading level seen by the sample rear face. Note that the existence of different and identical thicknesses in a same regime (cf. regimes D2, D3 and D4 in Table 4) indicates the statistical homogeneity of all the targets in spite of the fact that the thinnest one represents only 15 times the RVE (see Section 2.2).

We thereby obtained thresholds for the four damage regimes according to the stress endured by the target back face (see Table 4). However, they were estimated by means of the acoustic approximation, which cannot be totally trusted in the case of porous materials, and they should be refined thanks to further reliable simulations.

\subsubsection{Other shots analysis}

Apparently, six shots do not match with the four-damageregime ranking because their fragmentation does not look like any other. However, some of them have free surfaces velocities close to those of ranked shots. Post-mortem tomographies have been performed in order to detect eventual subsurface damage capable to clarify our analysis.

According to $U_{m}$, S10 and N16 should belong to D2 but imaging given in Fig. 13 does not show any typical double spall corresponding to this regime. Nevertheless, the tomographic slices on the same

Table 4

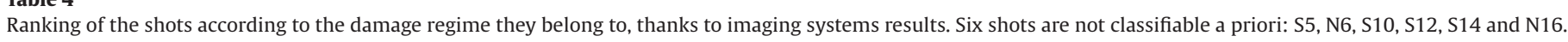

\begin{tabular}{|c|c|c|c|c|c|c|c|c|c|c|}
\hline \multirow{2}{*}{$\frac{\text { Regime }}{\text { Shot }}$} & \multirow{2}{*}{$\frac{\mathrm{D} 1}{\mathrm{~N} 13}$} & \multicolumn{4}{|l|}{ D2 } & \multicolumn{3}{|l|}{ D3 } & \multicolumn{2}{|l|}{ D4 } \\
\hline & & S7 & N11 & N18 & N26 & N9 & S15 & $\mathrm{S} 27$ & N8 & S17 \\
\hline Thick. (mm) & 2 & 0.75 & 1.5 & 1 & 1 & 1 & 0.75 & 1 & 0.75 & 0.75 \\
\hline$I_{m}\left(\mathrm{TW} / \mathrm{cm}^{2}\right)$ & 3.11 & 0.89 & 3.35 & 1.88 & 2.29 & 3.50 & 1.89 & 3.42 & 3.59 & 4.00 \\
\hline$U_{m}(\mathrm{~m} / \mathrm{s})$ & 99 & 169 & 163 & 194 & 190 & 332 & 272 & 320 & 511 & 564 \\
\hline$P_{m}(\mathrm{MPa})$ & 192 & 327 & 316 & 376 & 369 & 644 & 528 & 621 & 991 & 1094 \\
\hline
\end{tabular}


Regime D1
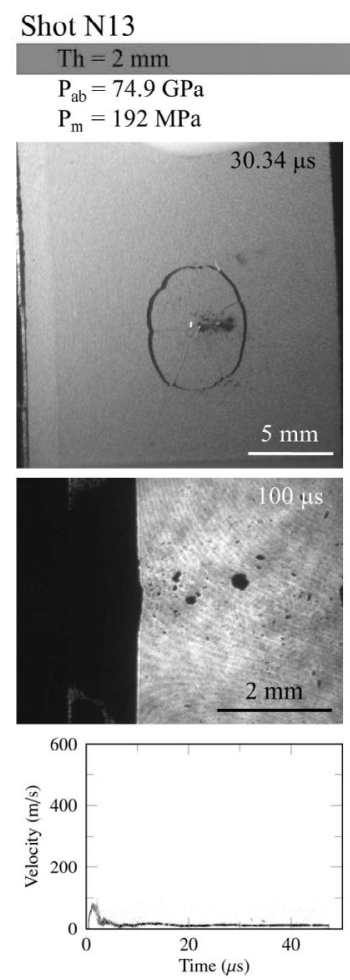

Regime D2

Shot N11
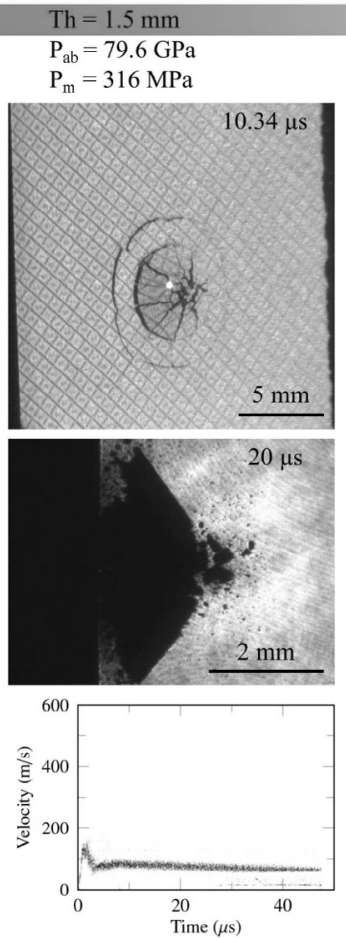

Regime D3 Shot N9

$\mathrm{Th}=1 \mathrm{~mm}$

$\mathrm{P}_{\mathrm{ab}}=82.5 \mathrm{GPa}$

$\mathrm{P}_{\mathrm{m}}=644 \mathrm{MPa}$
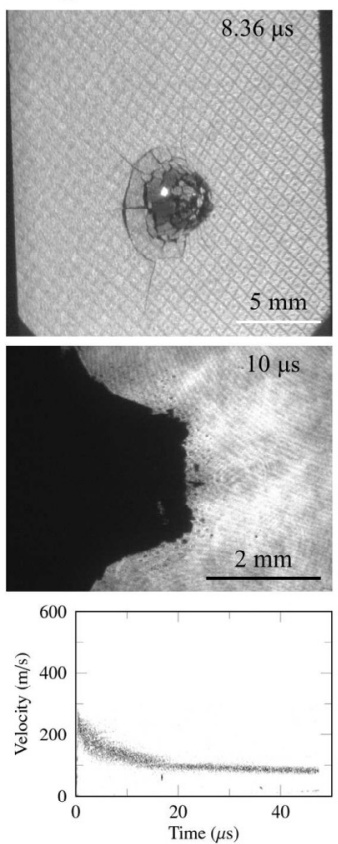

Regime D4 Shot N8

$\mathrm{Th}=0.75 \mathrm{~mm}$

$\mathrm{P}_{\mathrm{ab}}=84.2 \mathrm{GPa}$

$\mathrm{P}_{\mathrm{m}}=991 \mathrm{MPa}$
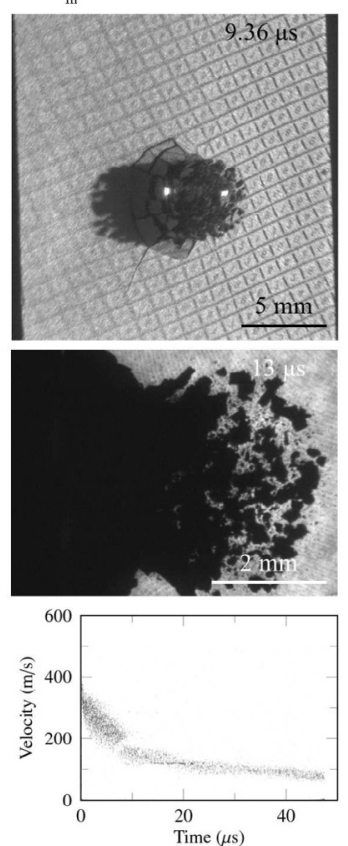

(a) North beam. Ablation pressure $P_{a b}$ is constant whereas target thickness is decreasing.

Regime D1

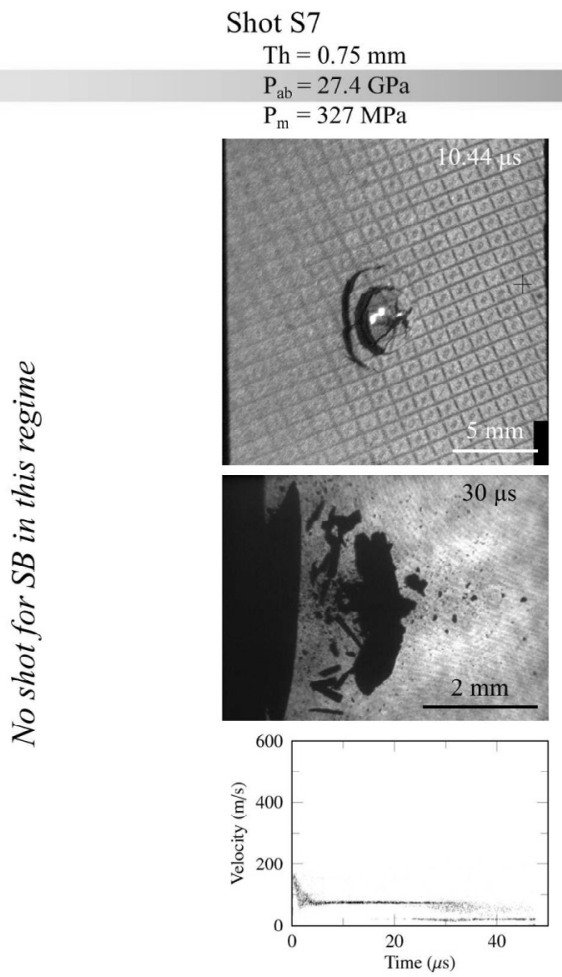

Regime D3

Shot S15

$\mathrm{Th}=0.75 \mathrm{~mm}$

$\mathrm{P}_{\mathrm{ab}}=50.4 \mathrm{GPa}$
$\mathrm{P}_{\mathrm{m}}=528 \mathrm{MPa}$
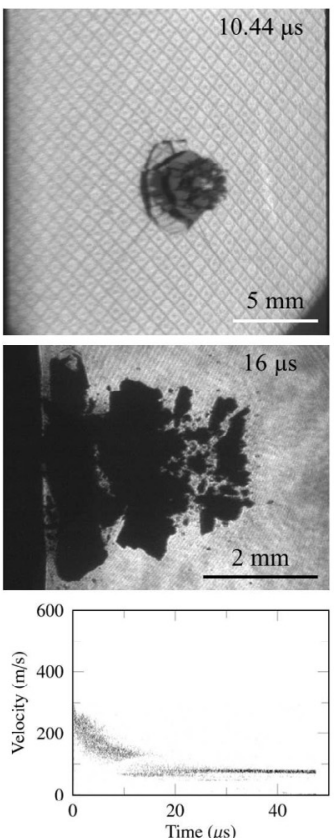

Regime D4

Shot S17

$\mathrm{Th}=0.75 \mathrm{~mm}$
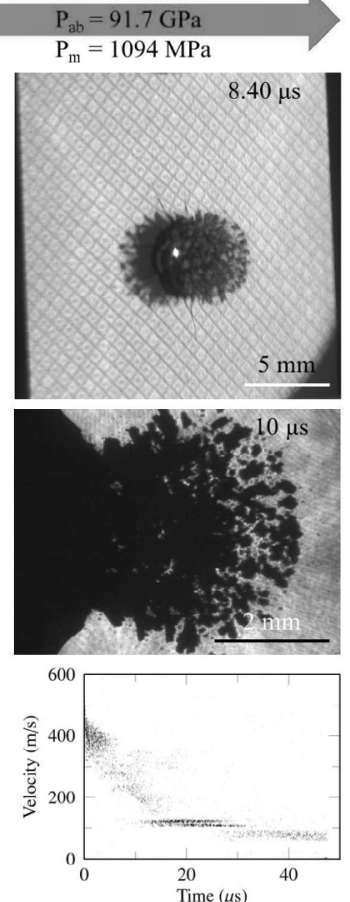

(b) South beam. Target thickness is constant whereas $P_{a b}$ is increasing. 


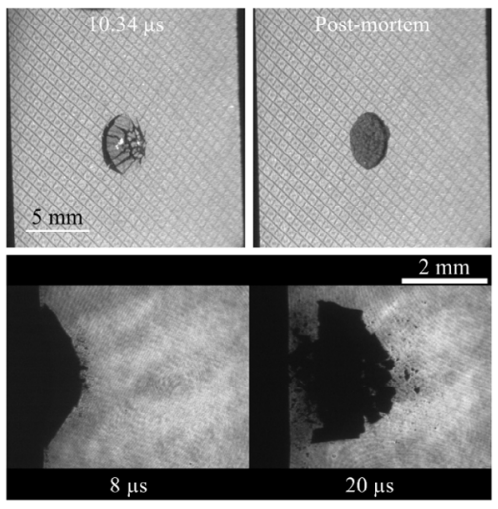

(a) Shot $\mathrm{S} 10-1 \mathrm{~mm}-1.72 \mathrm{TW} / \mathrm{cm}^{2}$.

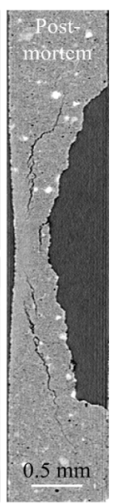

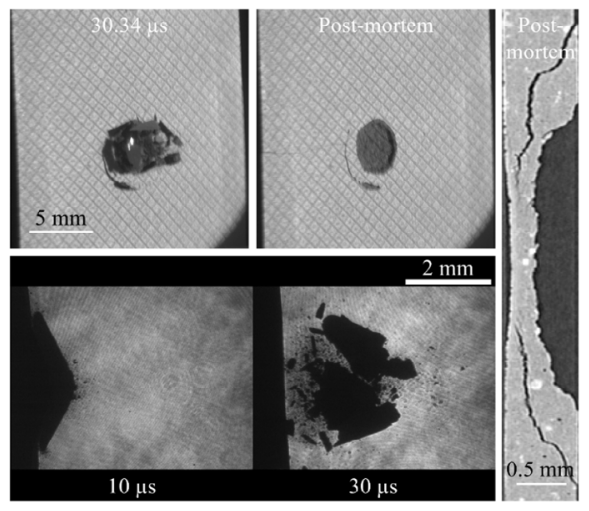

(b) Shot N16-0.75 mm - $0.92 \mathrm{TW} / \mathrm{cm}^{2}$.

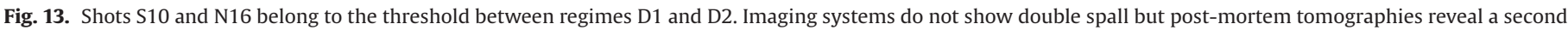

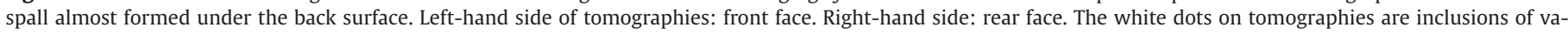
nadium and titanium from the graphite manufacturing process.

figure reveals subsurface cracks that have not completely or not at all reached the back face. Their shape suggests that a second spall was appearing but did not detach itself. Therefore, those two shots are at the threshold between D1 and D2, between a single and a double spall.

Given the velocities of shots S5, N6, S12 and S14, they could be logically linked to regime D1 but no damage was visible with the imaging systems. Fig. 14 presents tomographies of these targets.

The laser shock of shot S5 produced an important crater on the target front face but did not generate cracks nor crack initiations in the direction of the back face as shown in Fig. 14(a). S5 does not belong to any damage regime. Moreover, its free surface velocity is sensibly lower than the observed one for D1, i.e. $51 \mathrm{~m} / \mathrm{s}$ instead of around $100 \mathrm{~m} / \mathrm{s}$.

The tomography of shot S14 evidences a conical crack underlined in yellow in Fig. 14(d). If it had propagated up to the rear face, a conical spall would have been formed and ejected. Hence, S14 is probably at the threshold between no damage and regime D1.

It is harder to interpret shots N6 and S12. In both cases, tomographies reveal conical cracks facing the back surface. There are few hypotheses. First, if cracks had reached the back face, double or triple spall would have occurred and these two shots could not be ranked

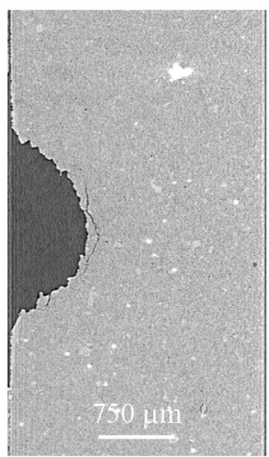

(a) Shot $\mathrm{S5}-2.5 \mathrm{~mm}$ $1.57 \mathrm{TW} / \mathrm{cm}^{2}$.

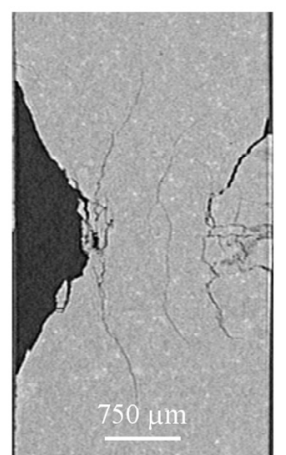

(b) Shot N6 - $2.5 \mathrm{~mm}$ $3.94 \mathrm{TW} / \mathrm{cm}^{2}$.
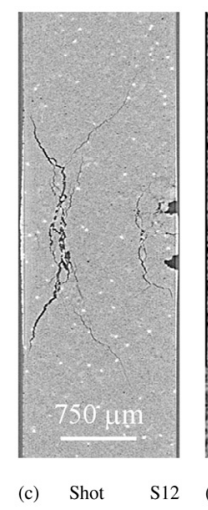

$1.5 \mathrm{~mm}-\mathrm{S} 14$ $1.38 \mathrm{TW} / \mathrm{cm}^{2}$.

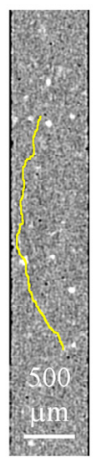

(d) Shot $0.75 \mathrm{~mm}$ $0.26 \mathrm{TW} / \mathrm{cm}^{2}$
Fig. 14. Tomographies of shots S5, N6, S12, and S14. The target fronts are left. The white dots are inclusions of vanadium and titanium from the graphite manufacturing process. For clarity, crack of S14 has been underlined in yellow. in regime D1. Second, if only the crack that is the closest to the front face had reached the back face, there would be a single spall. This is likely since it would lead to the perforation of both targets which has been noted for N13 (the unique confirmed shot of D1). Moreover, as the spall of this shot has not been recovered, we cannot know if it held in other crack initiations. In that case, N6 and S12 ranked somewhere between no damage and D2. Third and last, the creation of a large crater on the front face of the two shots may have strongly influenced the crack initiation and propagation in the deeper volumes. Damage regimes would thus not only be linked to the rear surface velocity but also to the target thickness, since large craters are formed onto the thickest ones.

\subsection{Damage characterization}

\subsubsection{Targets}

Tomographies presented in Figs. 13 and 14 show that, when it exists, the subsurface damage into the targets mainly takes the form of long conical cracks. It is the case of all shots up to the regime D2 included. Sadly, for shots of regimes D3 and D4, the belated strong flexions caused by the laser loading broke the targets into unrecovered multiple parts.

Shot S12 is of particular interest as it allows to learn how front face craters are formed thanks to Fig. 14(c). A crack propagates from the depth to the surface apparently leading to the ejection of a not or barely fragmented block of matter despite the fact that the front face endured pressures around $40 \mathrm{GPa}$.

All these post-mortem observations should be very helpful for a precise adjustment of the thresholds of further numerical failure models.

Finally, note that, even though the graphite-diamond phase transition pressure (18-28 GPa according to the SESAME 7832 table) has been widely exceeded for almost all the shots, no diamond phase has been observed on the tomography.

\subsubsection{Debris}

For shots N26 (D2) and S27 (D3), debris have been recovered thanks to varagel collectors. Tomographies have been performed in order to analyze their population. Fig. 15 plots for both shots the cumulated debris volume according to the particle volume. The two targets have the same thickness, i.e. $1 \mathrm{~mm}$. To allow the comparison, we neglect the potential shape effect of the laser beam on the ejected particles volume. 


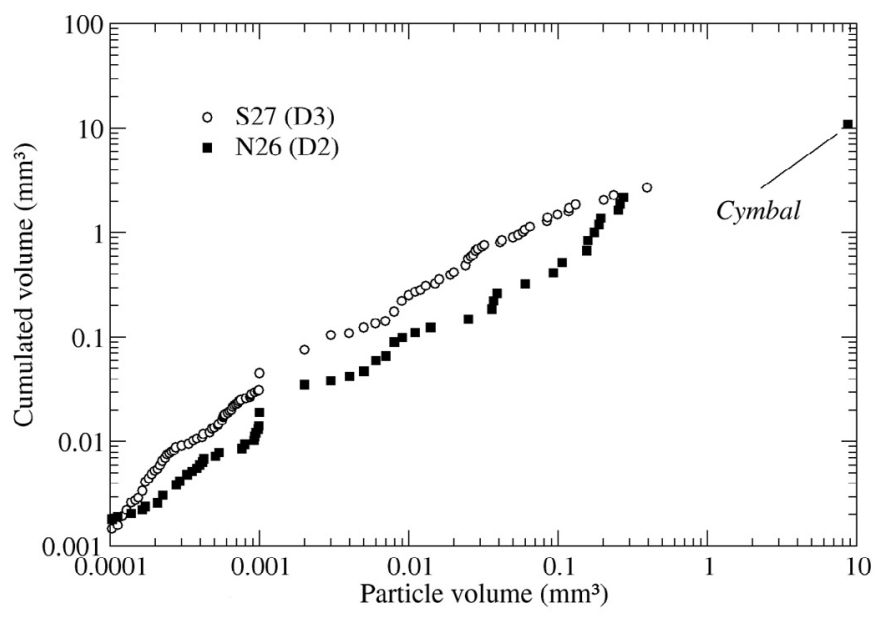

Fig. 15. Cumulated debris volume according to particle volume. The volume of ejected matter is greater for the lowest damage regime (D2). Particles are smaller for the highest regime (D3).

Unlike we could have anticipated, the volume of the ejected matter during the lowest shot (N26) is almost four times greater than for the highest shot (S27). The difference entirely comes from the cymbal-like debris observed in regime D2 since it accounts for three quarters of total volume of the debris. Once excluded, volumes become equivalent.

Differences in terms of debris population have to be noticed. Particles of volume between 0.0001 and $0.001 \mathrm{~mm}^{3}$ are more numerous for shot S27 (D3) than for shot N26 (D2) since the slope of the first one is steeper. The slopes are then equivalent for particles between 0.001 and $0.1 \mathrm{~mm}^{3}$ which indicates a similarity between the debris populations. Finally, beyond $0.1 \mathrm{~mm}^{3}$, the slope of shot N26 is the steepest which reveals its debris of this size are more numerous than for S27. These measures are consistent with our visual observations that show the size of debris is decreasing when the loading level increases. According to Grady's theory [39], it confirms that the strain rate is higher in D3 than in D2.

\section{Summary and future work}

Previous studies showed the shortcomings of classical impact tests (plates and spheres) in helping to understand the twodimensional damage phenomena of a commercial grade of porous graphite. This paper has demonstrated that a better insight can be obtained using well-calibrated and repeatable laser-driven shocks along with various in-situ and post-mortem diagnostics:

- Spall strength has been estimated thanks to PDV data;

- Precise VISAR records allowed to value the stress level seen by the rear face of the targets;

- High-speed imaging systems provided a dynamic visualization of damage and fragments and helped to understand unfamiliar long-time PDV spectrograms;

- Time- and space-resolved shadowgraphy confirmed velocity measurements;

- Fragment analysis and subsurface crack localization became available thanks to post-mortem tomography;

- Identification and comprehension of four damage regimes were possible because of a large crossed data reduction.

Given all the collected data, associated numerical works are currently being conducted and will be the subject of a further publication. Free-surface and fragment velocity, back-face deformations, crack localizations and fragment sizes, in conjunction with the space and time characterization of the laser pulse, will help to develop and adjust reliable models for shock wave propagation and damage into graphite. Then, the stress thresholds of the four damage regimes could be refined. Finally, similar experimental and numerical approaches could be conducted for other materials.

\section{Acknowledgments}

The authors would like to thank Yannick Pannier (Institut P' UPR3346) for his help conducting the tomographies and all the LULI staff members for their technical and administrative support during the campaign. The access to the Luli2000 facility was granted by the French Lasers and Plasmas Institute (ILP - FR2707).

\section{References}

[1] DeMichelis C. Laser interaction with solids - a bibliographical review. IEEE J Quant Electron 1970;6(10):630-41.

[2] Veeser LR, Solem JC. Studies of laser-driven shock waves in aluminum. Phys Rev Lett 1978;40:1391-4. doi:10.1103/PhysRevLett.40.1391.<http://link.aps.org/ doi/10.1103/PhysRevLett.40.1391>.

[3] Ng A, Parfeniuk D, DaSilva L. Hugoniot measurements for laser-generated shock waves in aluminum. Phys Rev Lett 1985;54:2604-7. doi:10.1103/PhysRevLett .54.2604. <http://link.aps.org/doi/10.1103/PhysRevLett.54.2604>.

[4] Eliezer S, Gilath I, Bar-Noy T. Laser-induced spall in metals: experiment and simulation. J Appl Phys 1990;67(2):715-24. <http://dx.doi.org/10.1063/ $1.345777>$, <http://scitation.aip.org/content/aip/journal/jap/67/2/10.1063/ $1.345777>$

[5] Boustie M, Cottet F. Experimental and numerical study of laser induced spallation into aluminum and copper targets. J Appl Phys 1991;69(11):7533-8. <http://dx.doi.org/10.1063/1.347570>, <http://scitation.aip.org/content/aip/ journal/jap/69/11/10.1063/1.347570>.

[6] Pirri AN. Theory for laser simulation of hypervelocity impact. Phys Fluids 1977;20(2):221-8. doi:10.1063/1.861859. <http://link.aip.org/link/?PFL/ 20/221/1>

[7] Nebolsine PE. Laser simulation of hypervelocity impact. In: AIAA 14th Aerospace Sciences Meeting; 1976.

[8] Phipps CR, Turner TP, Harrison RF, York GW, Osborne WZ, Anderson GK, et al. Impulse coupling to targets in vacuum by $\mathrm{KrF}, \mathrm{HF}$, and $\mathrm{CO} 2$ single-pulse lasers. J Appl Phys 1988;64(3):1083-96. doi:10.1063/1.341867.

[9] Grün J, Decoste R, Ripin BH, Gardner J. Characteristics of ablation plasma from planar, laser-driven targets. Appl Phys Lett 1981;39(7):545-7. <http://dx.doi.org/ 10.1063/1.92788>, <http://scitation.aip.org/content/aip/journal/apl/39/7/ $10.1063 / 1.92788>$.

[10] Fabbro R, Fournier J, Ballard P, Devaux D, Virmont J. Physical study of laserproduced plasma in confined geometry. J Appl Phys 1990;68(2):775-84 doi:10.1063/1.346783. <http://link.aip.org/link/?JAP/68/775/1>.

[11] Berthe L, Fabbro R, Peyre P, Tollier L, Bartnicki E. Shock waves from a waterconfined laser-generated plasma. J Appl Phys 1997;82(6):2826-32. doi:10.1063/ 1.366113. <http://link.aip.org/link/?JAP/82/2826/1>.

[12] Buresi E, Coutant J, Dautray R, Decroisette M, Duborgel B, Guillaneux P, et al. Laser program development at CEL-V: overview of recent experimental results. Laser Part Beams 1986;4:531-44. doi:10.1017/S0263034600002214. $<$ http://journals.cambridge.org/article-S0263034600002214>.

[13] Ramis R, Meyer-ter-Vehn J, Ramírez J. MULTI2D - a computer code for two-dimensional radiation hydrodynamics. Comput Phys Commun 2009; 180(6):977-94. <http://dx.doi.org/10.1016/j.cpc.2008.12.033>, <http://www .sciencedirect.com/science/article/pii/S0010465508004505>.

[14] Batani D, Strati F, Stabile H, Tomasini M, Lucchini G, Ravasio A, et al. Hugoniot data for carbon at megabar pressures. Phys Rev Lett 2004;92:1-4. doi:10.1103/ PhysRevLett.92.065503. <http://link.aps.org/doi/10.1103/PhysRevLett.92 $.065503>$.

[15] Laporte D. Analyse de la réponse d'assemblages collés sous des sollicitations en dynamique rapide. Essais et modélisations [Ph.D. thesis]. École Nationale Supérieure de Mécanique et d'Aérotechnique de Poitiers; 2011.

[16] Loison D, de Rességuier T, Dragon A, Mercier P, Benier J, Deloison G, et al. Skew photonic Doppler velocimetry to investigate the expansion of a cloud of droplets created by micro-spalling of laser shock-melted metal foils. J Appl Phys 2012;112:1-8.

[17] Bolis C. Étude numérique et expérimentale de la séparation par chocs brefs d'interface de revêtements multicouches. Application au test d'adhérence par chocs laser [Ph.D. thesis]. Université de Poitiers; 2004.

[18] Ecault R, Boustie M, Touchard F, Pons F, Berthe L, Chocinski-Arnault L, et al. A study of composite material damage induced by laser shock waves. Compos Part A Appl Sci Manuf 2013;53(0):54-64. <http://dx.doi.org/10.1016/ j.compositesa.2013.05.015>, <http://www.sciencedirect.com/science/article/ pii/S1359835X13001589>.

[19] Cuq-Lelandais JP. Étude du comportement dynamique de matériaux sous choc laser sub-picoseconde [Ph.D. thesis]. École Nationale Supérieure de Mécanique et d'Aérotechnique de Poitiers; 2010. 
[20] Holmquist TJ, Wereszczak AA. Laser-induced spall in silicon carbide. In: 23rd International Symposium on Ballistics; 2007.

[21] Holmquist TJ, Wereszczak AA. The internal tensile strength of a borosilicate glass determined from laser shock experiments and computational analysis. Int J Appl Glass Sci 2014;5(4):345-52. doi:10.1111/ijag.12097. <http://dx.doi.org/ 10.1111/ijag.12097>.

[22] Hébert D, Seisson G, Bertron I, Chevalier JM, Thessieux C, Quessada JH, et al. Plate impact experiments and simulation on porous graphite. J Phys Conf Ser 2014;500(18):1-6. <http://stacks.iop.org/1742-6596/500/i=18/a=182016>.

[23] Hébert D, Seisson G, Bertron I, Hallo L, Chevalier JM, Thessieux C, et al. Simulations of hypervelocity impacts into graphite. Procedia Eng 2015;103: 159-64. <http://dx.doi.org/10.1016/j.proeng.2015.04.022>, <http://www .sciencedirect.com/science/article/pii/S1877705815006967>; Proceedings of the 2015 Hypervelocity Impact Symposium (HVIS 2015).

[24] Seisson G. Hébert D, Bertron I, Chevalier JM, Lescoute E, Videau L, et al. Dynamic behavior of a porous brittle material: experiments and modeling. In: Sorensen B, Chhabildas L, editors. Procedia Eng 2013;58:715-23. <http://dx.doi.org/ 10.1016/j.proeng.2013.05.083>; Proceedings of the 12th Hypervelocity Impact Symposium.

[25] Seisson G, Hébert D, Bertron I, Chevalier JM, Hallo L, Lescoute E, et al. Dynamic cratering of graphite: experimental results and simulations. Int J Impact Eng 2014;63(0):18-28. <http://dx.doi.org/10.1016/j.ijimpeng.2013.08.001>, <http://www.sciencedirect.com/science/article/pii/S0734743X13001565>.

[26] Seisson G, Hébert D, Hallo L, Chevalier JM, Guillet F, Berthe L, et al. Penetration and cratering experiments of graphite by $0.5-\mathrm{mm}$ diameter steel spheres at various impact velocities. Int J Impact Eng 2014;70(0):14-20. <http://dx.doi.org/ 10.1016/j.ijimpeng.2014.03.004>, <http://www.sciencedirect.com/science/ article/pii/S0734743X14000724>.

[27] Jodar B, Seisson G, Hébert D, Bertron I, Boustie M, Berthe L. Enhancement of a dynamic porous model considering compression-release hysteresis behavior: application to graphite. Int J Impact Eng 2015;Submitted.

[28] Luli. Luli200. <wWw.luli.polytechnique.fr/accueil/les-installations/luli2000> 2014 [accessed 09.15].

[29] Barker LM, Hollenbach RE. Laser interferometer for measuring high velocities of any reflecting surface. J Appl Phys 1972;43(11):4669-75. <http://dx.doi.org/
10.1063/1.1660986>, <http://scitation.aip.org/content/aip/journal/jap/43/ $11 / 10.1063 / 1.1660986>$.

[30] Strand OT, Goosman DR, Martinez C, Whitworth TL, Kuhlow WW. Compact system for high-speed velocimetry using heterodyne techniques. Rev Sci Instrum 2006;77(8):1-8. doi:10.1063/1.2336749.

[31] Mercier P, Bénier J, Frugier PA, Sollier A, Le Gloahec Rabec M, Lescoute E, et al. PDV measurements of ns and fs laser driven shock experiments on solid targets. AIP Conf Proc 2009;1195(1):581-4. <http://dx.doi.org/10.1063/1 .3295205>, <http://scitation.aip.org/content/aip/proceeding/aipcp/10.1063/1 .3295205>.

[32] Hébert D, Hallo L, Voisin L, Desanlis T, Galtié A, Bicrel B, et al. A KDP equation of state for laser-induced damage applications. J Appl Phys 2011;109(12): 123527. <http://dx.doi.org/10.1063/1.3600210>, <http://scitation.aip.org/ content/aip/journal/jap/109/12/10.1063/1.3600210>.

[33] Loison D, de Rességuier T, Dragon A. Ballistic properties of debris produced by laser shock-induced micro-spallation of tin samples. J Phys Conf Ser 2014;500(11):1-6. <http://stacks.iop.org/1742-6596/500/i=11/a=112041>.

[34] Lescoute E, De Rességuier T, Chevalier JM, Boustie M, Berthe L, Cuq-Lelandais JP. Transverse shadowgraphy and new recovery technique to investigate dynamic fragmentation of laser shock-loaded metals. AIP Conf Proc 2009; 1195(1):1043-6. <http://dx.doi.org/10.1063/1.3294979>, <http://scitation.aip .org/content/aip/proceeding/aipcp/10.1063/1.3294979>.

[35] Frugier PA. Quantification 3D d'une surface dynamique par lumière laser structurée en impulsion nanoseconde. Application à la physique des chocs, du millimètre au décimètre [Ph.D. thesis]. Université Paris Sud; 2015.

[36] Poco. Poco website. <www.poco.com>; 2014 [accessed 12.15].

[37] Sheppard RG, Morgan D, Mathes DM, Bray DJ, editors. Properties and characteristics of graphite for the EDM industry. 5th ed. Poco Graphite, Inc. 2002.

[38] Seisson G. Étude expérimentale et théorique de l'endommagement du graphite sous sollicitation dynamique - Application aux impacts hypervéloces [Ph.D. thesis]. École Nationale Supérieure de Mécanique et d'Aérotechnique; 2014.

[39] Grady DE. Local inertial effects in dynamic fragmentation. J Appl Phys 1982;53:322-5. 